complicated one, and it will demand the combined efforts of experts and legislators for a generation; but if it be not considered with the definite intention of immediate action, we shall be held up to the deserved execration of our not very remote descendants.

The two great principles which I have alluded to in an earlier part of this address must not, however, be lost sight of ; they should guide all our efforts to use energy economically. Concentration of energy in the form of electric current at high potential makes it possible to convey it for long distances through thin and therefore comparatively inexpensive wires; and the economic coefficient of the conversion of mechanical into electrical, and of electrical into mechanical energy is a high one; the useless expenditure does not much exceed one twentieth part of the energy which can be utilized. These considerations would point to the conversion at the pit-mouth of the energy of the fuel into electrical energy, using as an intermediary, turbines, or preferably gas engines; and distributing the electrical energy to where it is wanted. The use of gas engines may, if desired, be accompanied by the production of halfdistilled coal, a fuel which burns nearly without smoke, and one which is suitable for domestic fires, if it is found too difficult to displace them and to induce our population to adopt the more efficient and economical systems of domestic heating which are used in America and on the continent. The increasing use of gas for factory, metallurgical and chemical purposes points to the gradual concentration of works near the coal mines, in order that the layingdown of expensive piping may be avoided.

An invention which would enable us to convert the energy of coal directly into electrical energy would revolutionize our ideas and methods, yet it is not unthinkable. The nearest practical approach to this is the Mond gas-battery, which, however, has not succeeded, owing to the imperfection of the machine.

In conclusion, I would put in a plea for the study of pure science, without regard to its applications. The discovery of radium and similar radioactive substances has widened the bounds of thought. While themselves, in all probability, incapable of industrial application, save in the domain of medicine, their study has shown us to what enormous advances in the concentration of energy it is permissible to look forward, with the hope of applying the knowledge thereby gained to the betterment of the whole human race. As charity begins at home, however, and as I am speaking to the British Association for the Advancement of Science, I would urge that our first duty is to strive for all which makes for the permanence of the British commonweal, and which will enable us to transmit to our posterity a heritage not unworthy to be added to that which we have received from those who have gone before.

WILLIAM RAMSAY

\section{THE FIRST UNIVERSAL RACES CONGRESS}

Thanks to the indefatigable energy and enthusiasm of Mr. Gustav Spiller, who was ably assisted by Mrs. Spiller and supported by a large and representative committee, a new departure in the history of the world has been made by bringing together representatives of many classes of varied peoples to confer on the problems connected with the contact of races and peoples. During the week of the congress there could be seen in the halls of the University of London men and women of all shades of color and of different religions in friendly converse or planning schemes for breaking down racial and other prejudice, as well as for the betterment of mankind. For the majority it was a very serious occasion, as it is evident that they would not have come from such great distances at considerable expense and trouble if they had not thought it 
worth while. From this point of view the sight was pathetic as well as inspiriting. It is too early to form an opinion as to what the permanent result will be; at all events, many grievances have been laid bare, and those who were not too engrossed with their particular troubles or obsessed with their pet panacea will realize that there are very many difficult problems to face, the solution of which can only be made by calm thinking and long, patient work. Sentiment and rhetoric may initiate reforms, but their realization is mainly due to what may be termed mechanical methods.

A permanent result of the congress is to be found in the volume entitled "Inter-racial Problems" (Boston, The World's Peace Foundation, 29 A. Beacon St.), which contains some sixty articles specially written for the congress by more or less well-known people of diverse nationality. The authors had time to consider what they had to write and thus were able to give data and reasoned argument, as well as, in some cases, to formulate a constructive policy. The essays are naturally of unequal merit, but collectively they constitute an informing book on many social problems. Some of the speeches were also logical, sane and constructive, but their effect must necessarily be more transient, and the sultry weather combined with the poor acoustic properties of the hall further minimized their importance. No discussion was possible under the circumstances, each speaker was necessarily limited as, to time, and many attempted to obviate this restriction by rapid utterance which really defeated their object. Even those who might have been expected to give data or argument may have felt that the conditions were unfavorable and so adopted a more rhetorical method. What has become of all the ideas that were promulgated? Unless there was an official stenographer the vast majority of them must have perished. No human being, even if he caught all that was said or understood the various languages that were spoken, could carry away more than a fraction of what he heard. A considerable number of patient souls seem to have sat through everything; if they appreciated all that transpired their minds must have become very confused and their feelings painfully lacerated.

Without the least-intention of being uncharitable, it appeared that a certain class wished to believe more than facts warrant. For example, because the anthropologists admitted that there was probably no race which would be described as pure, therefore races were chimerical; because skin-color is not of primary value in classifying peoples, the official program speaks of "so-called white and so-called colored peoples"; because the environment produces changes in certain physical characters (but to what extent, in what time, or how permanent they may be in modern times, we have practically no information) the classification of human varieties is a vain task. One anthropologist "swam against the current to the congress" by asserting that "the brotherhood of man is a good thing, but the struggle for life is a far better one." Another said he did not agree that all races were equal or that the differences were due solely to environment. It was not for the good of the world that all races should be equal, nor would they ever be, but it was desirable that all should have an equal chance of development. A third hoped that the ideas and ideals of various peoples would remain distinct and not merged into a common type of humanity. All agreed that there should be a sympathy based on mutual knowledge and forbearance among different nationalities. Taken from one point of view, much that was said by the anthropologists might be construed as supporting the views of a large number of the members of the congress, but the latter seem to have overlooked the very important element of time. Dr. C. S. Myres in his printed paper says: "If we assume, as I think we must assume, that the white and negro races owe their respective characters ultimately to their environment, there is no a priori reason, it seems to me. for denying the possibility of a reversal of their [mental and physical] differences, if the environment to which they are respectively exposed be 
gradually, in the course of many hundreds of thousands of years, reversed." In some speeches often unmerited blame was bestowed on systems of government or on government officials without a due consideration of the special circumstances or the difficulties of the situation. What so many ardent spirits can not appreciate is that safe progress is slow progress and that compromises have to be made. Another fallacy was manifest in the belief that one system of government is suitable for all types of humanity. But most of the obvious defects were just those which were practically inevitable; the delegates and others were mainly those who came in response to strong emotion, and desired to draw attention to their own or their friends' grievances.

The social atmosphere was highly charged. They wanted things said in the hope of getting things done. Each fanned the flame of his own enthusiasm and that of others. There is no doubt that the congress has resulted in much friendliness between members of different nations, perhaps some misunderstandings have been removed, conscience has been stimulated, but the prosaic work remains to be done.

\section{A. C. HADDON}

\section{THE MARINE BIOLOGICAL LABORATORY}

THE investigators working at the Marine Biological Laboratory at Woods Hole, during a part or the whole of the season, have been as follows:

Abbott, James Francis, professor of zoology, Washington University, St. Louis.

Abbott, Margaret B., Bennett School, Millbrook, New York.

Addison, W. H. F., demonstrator of histology and embryology, University of Pennsylvania.

Allyn, Harriet M., fellow in zoology, University of Chicago.

Amberg, Samuel, associate professor of pediatries, Johns Hopkins University.

Bancroft, Frank W., associate, Rockefeller Institute for Medical Research, New York City.

Bartelmez, George W., associate in anatomy, University of Chicago.

Beckwith, Cora J., instructor in biology, Vassar College.
Beutner, Reinhard, assistant, Rockefeller Institute for Medical Research.

Bradley, H. C., assistant professor of physiological chemistry, University of Wisconsin.

Browne, Ethel N., graduate student, Columbia University.

Budington, Robert A., associate professor of zoology, Oberlin College.

Calkins, Gary N., professor of protozoology, Columbia University.

Chambers, Robert, lecturer and laboratory assistant in zoology, University of Toronto.

Clapp, Cornelia M., professor of zoology, Mount Holyoke College.

Conklin, E. G., professor of zoology, Princeton University.

Craig, Wallace, professor of philosophy, University of Maine.

Curtis, W. C., professor of zoology, University of Missouri.

Davis, Sarah Ellen, 512 West 132d Street, New York City.

Derick, Carrie M., assistant professor of botany, MeGill University.

Donaldson, H. H., professor of neurology, Wistar Institute of Anatomy and Biology, Philadelphia.

Dodds, Gideon S., instructor in zoology, University of Missouri.

Drew, Gilman A., assistant director, Marine Biological Laboratory.

Duggar, B. M., professor of plant physiology, Cornell University.

Dungay, Neil S., professor of biology, Carleton College, Northfield, Minn.

Dunn, Elizabeth H., instructor in anatomy, University of Chicago.

Eddy, Milton W., Northwestern University.

Ennis, Agnes, 453 Convent Avenue, New York City.

Ferguson, J. S., assistant professor of histology, Cornell University Medical School, New York City.

Fox, Henry, professor of biology, Ursinus College, Collegeville, Pa.

Glaser, O. C., assistant professor of zoology, University of Michigan.

Goldfarb, A. J., instructor in zoology, College of the City of New York.

Harvey, Basil C. H., assistant professor of anatomy, University of Chicago.

Harvey, E. Newton, Columbia University.

Hogue, Mary J.

Just, E. E., Howard University, Washington, D. C. 